\title{
Research on Preschool Teachers' Safety Education in China
}

\author{
XiaoFen Wang* \\ College of Education science, NanTong University JiangSu Province, China, 226019
}

\begin{abstract}
In order to study the present situation of teachers' safety educational practice, and provide guidelines on how to carry out safety educational activities, we use the method of distributing questionnaires to 823 preschool teachers from different classes of kindergartens in four districts from $N$ city of JiangSu province. Through research, we got the result that teachers who often carry out this activities are (88.9\%). The main content of safety education include anti-lost, anti-electric shock, anti-kidnapping, anti-sharp objects and traffic safety; They conduct safety activities mostly by telling stories (45.1\%) and showing examples (34.0\%), also by prohibiting (18.9\%) and educating after the case occurred (2\%); Teachers also offered safety knowledge education to parents more often by the way of parents meeting, written form and Internet and rarely use the scene simulation. Preschool teachers have some problems in the behavior of safety education, and these qualities must be improved.
\end{abstract}

Keywords: preschool teachers; safety education practice; safety education method.

Safety issue affects every child and happy life. of every family. The development of children's physical and mental development have their own particularity, the characteristics of child's physical and mental development need adult's careful and comprehensive care and protection in order to make sure not to be injured or to reduce the damage of children when the accident happened [1].That need the teacher to have better knowledge and technique on keeping children safe when they are in emergency. Research of foreign scholars found that teachers pay more attention on children's safety and have more specialized knowledge and skills than children's parents. Because more and more teachers have realized if they want to be a qualified teacher they must have relevant knowledge of safety education and skills in order to carry out safety education .activities [2]. As the author of this article, I found through the literature checking that the literature relevant to the child's own safety cognition, is relatively more than literature focusing on safety of preschool teacher education and actual behavior. In this paper, the researchers carried out investigation during the time from march to May in 2016 on paying attention to teachers specific safety education behavior in $\mathrm{N}$ city kindergarten.

\section{Sample And Method}

\subsection{Sample}

By randomly stratified cluster sampling method, we carry out questionnaire investigation in 45 kindergartens in different grades in the District of $\mathrm{N}$ city in JiangSu province. We selected about 20 teachers randomly in every kindergarten and all the teachers we selected are 867. A total of 847 questionnaires were collected, 823 questionnaires are valid and the effective recovery rate is up to $94.9 \%$. The results were as follows: A total of 823 questionnaires were collected, all teachers are female. $8 \%$ teachers teaches are in nursery class, $27.3 \%$ teaches in low grade classes and $28.3 \%$ and $36.4 \%$ of the teachers teaches in middle class and senior class; teachers whose teaching age under 3 years accounted for $24.6 \%$, 3 7 years accounted for $40.1 \%$, more than 8 years accounted for $35.3 \%$, Those who has bachelor degree or above accounted for $31.4 \%$, tertiary education accounted for $68.1 \%$, high school or technical secondary school degree only $0.5 \%$.

\subsection{Method}

Using the method of questionnaire, content of questionnaire covers Kindergarten (including the name, nature, level) and the basic situation of teachers (including gender, education level, class, age, title, etc.) detail information to carry out safety education activities (including frequency, content and method). 


\subsection{Statistical Analysis}

The effective questionnaires were collected by SPSS16.0; use the software to analyze the percentage of descriptive statistics.

\section{RESUlT}

\subsection{Frequency of Safety Education}

$88.9 \%$ teachers often (three times a week) carry out safety education activities; $9.8 \%$ of teachers sometimes (1-2 times a week) carry out safety activities; less than $1.3 \%$ of teachers (less than 1 times a week) carry out related activities.

\subsection{Content of Safety Education}

On this multiple selected topic "On weekdays, what aspects of the safety education for children you carried" Those teachers who carry out anti-lost education accounted for $95.2 \%$. Those who carry out anti-abduction education accounted for $93 \%$. Those who carry out anti-sharp objects harm education accounted for $92 \%$.

Anti-electric shock education accounted for $90.9 \%$. traffic security education accounted $90.4 \%$. safety emergency telephone education accounted for $83.4 \%$. food safety education accounted for $79.9 \%$. drowning prevention education accounted for $77.5 \%$. earthquake education accounted for $59.9 \%$. drug safety education. accounted for $63.1 \%$.

\subsection{Safety Education Method}

To the topic "what are the main method you use on safety education for children," $45.1 \%$ of the teachers use telling stories and reading. 34\% teachers using the examples that can be held around to remind the children. There are $18.9 \%$ teachers tell no to children directly. Only $2 \%$ of the teachers choose to tell them after the incidence happened on children.

\subsection{Ways to Provide Parents with Knowledge of Safety Education}

To this multiple topic "what is the way you provide safety education knowledge to parents?" $88.2 \%$ teachers do so by holding lectures or meeting of parents. $85 \%$ teachers do so through the combination of writing and network communication. $76.5 \%$ teachers do so by organizing parents open day. $66.7 \%$ teachers do so by providing help to the individual teachers. $40.5 \%$ do so by demonstration in on-site simulation. 53.6\% teachers do so by holding friendly activity between kind-garden and family.

\section{DiscuSSION AND SuggeSTION}

There are some problems in kindergarten teachers' safety education which need to be adjusted and perfected.

\subsection{Ensure the Universality of Safety Education Activities}

Our research found that although the frequency of safety education activities is relatively among kindergarten teachers, but there are still some teachers who seldom carry out safety education activities. This is mainly because these teachers are busy completing various teaching task and have no enough time on the expense of safety education. So in the future, We should still pay attention to carry out safety education among children, maintain or increase the frequency of safety education activities and cannot let it down.

The Department in charge of education should understand the importance of safety and health education thoroughly, strengthen its supervision and management with regularly check and evaluating on the effect of the kindergarten's safety education activity. The kindergarten should also study children safety education and find its regulation. Then formulate safety education system, make relevant work plan, set the goal of education, mandatory the frequency on carrying out safety education. Make sure the quality of safety education by establishment of supervision team..

\subsection{To Ensure the Comprehensiveness and Balance of Safety Education}

We found that there are some problems like not comprehensive in kindergarten teacher's selection of safety education content. Anti-lost, anti-electric shock, anti-kidnapping, anti-sharps objects hurting and traffic safety education ate in high frequency because they are common in life and easy to happen on any of the children, while activities which connected with food safety and drug safety education 
are rarely paid enough attention by teachers. So we must pay enough attention on food and drug education in case of food poisoning or a foreign objects into the body of children just because of their lack of life experience, safety identification ability and self-control [3] Therefore, such educational activities should not be ignored.

Teacher in kindergarten should fully understand the aim children should attained at every step on "have the basic safety knowledge and self-protection ability" according to the specific requirements of safety education for kindergarten in the issued "3-6 year old children's learning and development guidelines" by the Ministry of Education. After that, teacher should carefully comb the target which not only includes the common and often occurs danger in child's life but also include less but equally important danger (such as disaster prevention, safety signs, self-help knowledge) by combining with the local actual situation and the child's true life in order to carry out the relevant activities efficiently and effectively. Teachers should also pay attention to the current social affairs and carry out the education in time.

\subsection{Methods of Enriching Safety Education Activities}

This study found that teachers carry out safety education through telling stories, reading books and showing examples. We can see from the ways they use that most teachers have considered the physical and psychological characteristics of child's education, by using vivid, concrete and lively method. But there are nearly $1 / 5$ teachers do so by " telling the child not to do something" which is a simple and direct way of education, these teacher warn their children with language of risk or the use of threats, intimidation and other means to get the end of prohibiting children not close to. That make children only to know "what it is", rather than "know why it is so", that possibly even play opposite. role [4] The method of safety education should be combined with the characteristics of physical and mental development of children, with vivid and entertaining, especially with the experience and education [5]. To this end, teachers should continue to enrich the form of activities.

On the other hand, in the special safety education, in addition to telling story, showing example, teacher can also use network video, animation and other materials, network animation has become an important way in safety education, some abstract safety rules will be visualized in child's animation [6] Game playing is also an important way of safety education, It can be used in educating kid how to escape from fire, earthquake and other natural disaster. As foreign researchers suggested, some courses can be carried out on story carpet, some are in dance region, there is also an individual or a group of children study around a table, also may be in the play area [7]. In addition to carry out specialized safety education, safety education should also be carried out in actual daily life, such as remind children attention on some safety issue when they go out. Help children understand things unsafe in the surrounding environment and not to do dangerous things.

\subsection{Enrich the Way of Knowledge Propaganda to Parents}

From the above discussion, we know that there are many ways for teachers to provide safety knowledge to parents. In addition to providing theoretical knowledge to parents through parental lecture, setting up safety column and network etc. kindergarten teachers can also drill for parents during parent meeting and parents open day, let the parents participate in the security exercises with the actual experience, strengthen the experience frequency by field simulation, improve the safety education level of parents and improve the effect of safety education activities.

\section{REFERENCES}

[1] Jing Xiang. Study on safety emergency literacy of preschool teachers [D]. Hubei: Huazhong Normal University, 2014:2.

[2] Yuto Kitamura. possibility holistic safety in From perspective of Education Sustainable Development (ESD) [J]. Iatss Reseach, 2014, 38 (1): 40-47.

[3] Jingping Niu, Rong Li etal. Analysis of influencing factors of children's safety awareness in Lanzhou [J]. School of health of China, 2003, 24 (4): 315-316.

[4] Xiao fenWang. Current situation of migrant children's parents' safety knowledge and safety education in China[J]. School of health of China, 2016, 37 (2): 187-189.

[5] Jing Li Lu Bai. The actualities of Chongqing kindergarten safety education survey [J]. Chinese school health, 2010, 31 (3): 353-354. 
[6] Zhen Liu, YanJie Chai. Web-Based Interactive Animation for Children's Safe Education: From 2D to 3D.from Anne Xie, Xiong Huang (Editors): Advances in Computer Science and Education [M], Springer ebooks, 2012, 140:403-407.

[7] E. Audrey Clark, Robert Simmons. Safety Concepts and Early Childhood Education: An Integrated Curriculum [J]. Day Care and Early Education, 1991, 18(3):17-21. 